\title{
OPEN SPACES: THE NEW FRONTIER FOR ACADEMIC WRITERS
}

\author{
P. Moodley \\ Department of Marketing and Retail Management \\ Durban University of Technology \\ Durban, South Africa \\ e-mail: padhmam@dut.ac.za
}

\section{ABSTRACT}

In the face of the 'fees must fall' campaign and severe budgetary constraints for South African universities, funding has become a challenge. To this end, institutional management bodies look to academics to fill the gaping void of reduced budgets through increased research output. This has sparked the need for institutions to provide support in the form of writing retreats for academics. The current study offers a critical examination of the experiences of academics on writing retreats, as well as the barriers they encountered once the retreat was over. Data was collected via qualitative in-depth interviews $(n=3)$. Content analysis was carried out on the data which revealed barriers to publication such as the need for additional support and time constraints. On this basis, this study recommends a model for Publication Improvement which is proposed to address the barriers academics encountered.

Keywords: writing retreats, peer support groups, publications, research output

\section{INTRODUCTION}

The cliché 'publish or perish' that is often associated with academics is a blunt reality that academics encounter. Yet writing for publication is an integral part of being an academic. However, there are a number of issues and challenges that confront academics, which prevent this from happening as often as it should. For instance, heavy workloads made up of large classes, heavy teaching loads, marking and administration plague many academics, as well as the frequent student disruptions and protests which all contribute significantly to their working lives. Institutions are aware of this, and recognize the impact these issues have on its research output. However, a decreased research output could have severe financial implications for institutions, especially in the South African context. In their own best interests as well as those of academics, interventions to increase publications have been promoted. Some of these interventions are identified as writing courses, peer support groups and writing retreats (McGrail, Richard and Jones 2006, in Murray and Cunningham 2011, 832). The various stages of these interventions allow for developing researchers, who lack certain skills, to publish. Attempting to address issues such as the lack of time, capacity and the inability to target relevant journals, at a writing retreat might seem ambitious, however without trying there will be fewer 
opportunities for institutions to increase their outputs.

This article aims to examine the experience of academics who have been on writing retreats and directs its focus to the barriers they encountered after the writing retreat. Furthermore, this article proposes a model to enhance the progression of publications once the retreat is over. Furthermore, the application of this model may have positive implications for academics wanting to publish. This does not imply that attending a writing retreat is a solution to a parched publication record; it may, however, remedy the symptoms, but the cure rests with the post-retreat strategies which academics engage, in order to publish.

\section{Writing retreats and what they mean to some universities}

According to Murray, Steckley and Macleod (2012, 766) the modern form of writing retreat is an approach to supporting academics' writing skills. Murray (2012) describes this as a process of going off campus for dedicated time and space to write. The idea of retreats is grand in its design to remove the academic to a more solitary space: something more opened, less confined to the desk and chair scenario. This is by no means separating the writing task from the academic's main duties (a process of engaging and disengaging), but instead finding a sense of integrating writing into their daily activities.

Murray and Cunningham (2011) identify key features of writing retreats as collegiality, peer discussion and dedicated writing time and space. Some retreats include input on writing for publication from facilitators or journal editors. However, the emphasis rests very much on academics being relieved of academic duties for a short period of time, in order to increase or improve the quality and quantity of publications. Unfortunately, the time at a retreat is insufficient to produce an article for publication, but it is meant to accelerate a process which must continue after the retreat.

As a proportion of institutional funding may be derived from research outputs, there has been a need for increased productivity at universities (Kramer and Libhaber 2016) in order to generate income. The \#FeesMustFall campaign that has swept through student bodies at universities in South Africa achieved enormous success in 2015 during their drive for a 0 per cent fees increase in the following year. This inadvertently placed massive financial pressure on institutions which were affected. The agenda for 2016 remained unchanged, as students vied for another success. The proposal for a 0 per cent increase has however been seen by some as being highly politicised in the face of a poorly performing economy. This has placed pressure on academics to either 'publish or perish' in an environment already charged by protest actions. 


\section{Capacity development for increased research output}

The need for capacity development amongst academics is dire as Segrott, McIvor and Green (2005, in Frantz 2012) concluded in their study on the promotion of research productivity among academics; they proposed that departments needed an overall approach that translated into clear strategies, which were well managed and evaluated. The authors further highlighted that very little feedback is given in terms of the processes and outcomes involved in capacity development initiatives. Furthermore, the role academic departments needed to take in developing strategies that are precise which must ensure effective communication, leadership and managerial commitment regardless of the capacity development interventions.

These findings reveal a number of gaps within the retreat process, which implies that further support is required once the retreat is over. Questions can be raised as to what followon processes are carried out to ensure more effective outcomes of the retreat. Murray (2012) highlights that academics experience difficulty in managing the completion of tasks, particularly in writing for publication. In a study conducted on a writing retreat, the analysis of the data revealed that the facilitative leadership provided at the retreat was central to managing task complexity and writing-related anxiety.

Writing retreats cannot exclusively deliver the results and outcomes institutions seek in preparing the academic to publish frequently: instead they gradually build capacity for academics to develop their writing skills. There are writing retreats which focus on postgraduate students who must learn how to formulate their writing in an academically publishable manner; there are retreats which focus on those who know how to write yet do not have the time to write, and there are retreats for those who are new at writing for publication and are intimidated by being rejected by a journal. To address these diverse needs, institutions must continue to build capacity and strategize to ensure that academics are adequately equipped to write for publication.

\section{Open spaces: The new frontier for academic writers}

The title of this article speaks to the academic who needs to find a rhythm in writing and eventually publishing. The duality of the term 'open spaces' necessitates a brief discussion on what this really means: the daily duties of an academic, which may include lecturing, marking, planning, administration as well as community engagement, may not permit the time needed for research. However, this usage of open spaces is about locating a space within those duties which should be dedicated to writing. The other view of open spaces refers to the physical location of where the writing takes place: this place or space could be on-campus or anywhere 
off-campus. In other words, writing requires physical engagement with dedicated writing time and space. Murray (2012) describes the experience of her research respondents in this regard, when she reports that finding the appropriate physical space to write was difficult for them; most wrote at home, which was not ideal for everyone and unfeasible for some. In another study conducted by Murray (2012, 82), respondents stated the 'need to disengage from places where interruptions occur, from spaces where other tasks have priority and from virtual spaces where other academic work is done'. A further study by Murray et al. $(2012,772)$ found that half of the respondents spoke of the benefits of the retreat in terms of space, support for thinking through and making sense of their own writing projects, or writing for publication more generally.

Ultimately writing requires dedicated time and space: however, an additional challenge is that not all academics are strong on their own, and many struggling academics require the assistance of others. To address this issue, Grant, Munro, McIsaac and Hill (2010) point out that writing groups are the dominant model for writing support.

\section{Writing in groups}

In their study, Grant et al. $(2010,54)$ mention that group members sought to develop their individual portfolios as writers. Furthermore, group members believed that the 'collegial approach to work, the regularity of meetings and the report back to trusted peers has been a key component of their individual success'. This structured approach to writing moved academics from individually attempting to pursue their scholarly writing activity into a 'community of writers'. Murray and Moore (2006), Aitchison (2009, in Murray 2012) suggest that writing in groups, which may or may not be led by a facilitator, provides a collegial and supportive environment in which writing is seen as a social activity that benefits from discussion between peers. Grant et al. (2010, 47) report that group members shared roles rather than having a single facilitator, taking turns in chairing meetings, taking the lead as well as submitting writing for peer assessment.

Steinert, McLeod, Liben and Snell (2008) advise that writing groups, designed to support and assist the writing process, may help to overcome writer's block and increase writing productivity. In a study conducted by Steinert et al. (2008, 281) - following a writing workshop - participants were invited to attend a series of three two-hour peer writing groups over a six month period. The goal was to help participants to overcome the challenges of working alone and to 'maintain their interest, work on specific sections of their manuscript, with peer support and feedback and discuss appropriate journals for publication'. One year later, nine participants 
submitted a total of 14 manuscripts, 11 of which were accepted for publication. In addition, 10 participants presented a total of 38 abstracts at educational meetings. Participants rated the workshop as very helpful (4.2 on a 5-point scale) and noted that the small groups, peer writing group meetings, and workbook were the most helpful components of this intervention.

The model that this article proposes is based on the premise of continuing group support once the retreat is over. This was concluded from the literature review as well as the findings that emanated from the study, which examined the post-retreat experience of academics and the barriers that they encountered.

\section{METHODOLOGY}

Research using the qualitative method allows one to explore the 'how' and 'why' of systems and human behaviour and what governs these behaviours (Edmonds and Kennedy 2013, 112). Data gathered in this study came from in-depth interviews $(n=3)$ held with three participants who had experience of a writing retreat; in addition, a focus group was held with four participants who shared similar experiences. The participants in this study did not attend the same retreat; instead their experience of attending retreats over the years forms the basis of this study. The resulting triangulation of the data contributed to the soundness of the findings in this study. The academics who participated provided rich data from which important findings were drawn. It must, however, be pointed out that the researcher has no intention of generalising the findings of this study, which would require an alternate research approach and a much larger sample; instead the primary focus was to analyse the experience of academics after attending a retreat, thereby prompting the proposal of a new model to encourage publications.

Convenience sampling was used to select the participants for the study, who came from three universities in South Africa. The interviews lasted between 20-40 minutes, and semistructured questions were asked by the researcher. The responses were audio recorded with the permission of the participant after which they were transcribed to allow for rigorous data analysis.

The focus group was conducted at a neutral venue where the participants were introduced to each other: each shared their experiences of attending writing retreats and the period that followed after the retreat was over. Discussions were initiated by the researcher and directed according to the objectives of the study. The responses were audio recorded and analysed afterwards to generate the findings of this study. 


\section{DATA ANALYSIS}

The qualitative nature of the study required that a detailed analysis of the data be carried out. The researcher applied a content analysis as well as a thematic analysis to the data owing to the nature of the objectives of the study. The main purpose or aim of the study was to ascertain what occurred with the participants' writing after attending the writing retreat. The data collected from the interviews were transcribed, after which the researcher coded the main areas of the responses which contributed to the objectives of the study. A process of data reduction was applied where this part of the analysis 'sharpens, sorts, discards and organised data in such a way that specific conclusions can be drawn’ (Miles and Huberman 1994).

The data was then coded, summarised and categorised to reveal important and key issues which responded to the objectives of the study. For this analysis, the researcher evaluated the frequency of words and phrases in response to the interview questions, using common words from which themes were generated. These themes were then analysed further to determine the findings of the study. A similar process was applied to the responses from the focus group.

\section{RESULTS AND DISCUSSION}

The results of the study are reported according to the major themes that emerged from the study. The study sought to examine the experience of academics who have been on writing retreats and to identify the barriers they encountered after the writing retreat. The following themes emerged in examining the benefits of the experience of academics who had been on writing retreats:

- $\quad$ Redirected focus on research

- Beneficial uninterrupted time

- $\quad$ Improved writing abilities

The themes that emerged as barriers that participants encountered once the retreat was over were:

- $\quad$ The need for additional support

- $\quad$ The lack of time to complete the paper/article

- $\quad$ The feeling of isolation

These themes are now explored further to determine the findings of the study. 


\section{Redirected focus on research}

The discussion in the focus group among the four participants highlighted the redirection of their focus to research as the predominant result of the writing retreats they had attended. The change in the environment, as well as the removal of responsibilities that routinely fill up their time, helped them focus on research. The participants revealed that it provided an opportunity to relook at their areas of specialisation and to examine newer areas for research. One of the participants stated: 'I am usually so wrapped up in the deadlines for assessments and marking that I have allowed this to consume my time and have lost out in tracking what is really going on in the real world'. This gave an indication of how academics 'allow' or permit certain tasks to have pre-eminence over other potentially more important ones. As MacLeod, Steckley and Murray (2011) state, in higher education, there is not one primary task but multiple and competing tasks, and several tasks may be ascribed primacy at any given time. Another participant who was interviewed, indicated that 'If I do not factor in research within my time, I will never have the time for it'. Managing time in the life of the academic is very important, especially to create a space for research within the work-plan of the academic.

\section{Beneficial uninterrupted time}

As has been stated, the writing retreat experience does provide uninterrupted time away from the routine of day to day tasks. The interviewed participants as well as the focus group participants indicated the benefits of the uninterrupted time, with one participant noting, 'it is very difficult to concentrate or get into the writing zone when students are at your door'; another stated 'if I could have three days every month without interruption, I would be able to work on a paper'; a member of the focus group explained, 'Writing should be our bread and butter, yet with the heavy workloads it becomes almost impossible to write. Not having the phone ring or my door pounded on actually is what I need to focus on putting an article together'. Another member of the focus group highlighted 'I am able to spend valuable time with like-minded individuals who experience the same issues I do. I can use this opportunity to fix the problems I have in writing'. This gave an indication of unresolved problems academics face in the area of research output, which restricts their progression in terms of promotion. An interview participant stated 'I have the time now to pull myself towards myself and to be able to examine the shortcomings in my life as an academic. Now I will just need more time to fix it!' The most important factors in facilitating publication, besides the scientific content of the article, appears to be a combination of a commitment of time and good writing skills (Kramer and Libhaber 
2016).

Engulfed with heavy workloads, research is the one area which can suffer, because it has very little bearing on the student. Yet it has the most impact on the reputation and financing of the academic and the institution.

\section{Improved writing abilities}

Writing is key to the survival of the academic, however there are many who perish along the way without receiving proper assistance in this area. The interviewed participants confirmed that the writing retreats they attended did help them identify the issues that prevented them from producing good articles. One participant stated 'I received such horrible feedback from a reviewer once that I refused to write again'. Here the academic did not lack the ability to write, but needed to improve on it through a more structured approach. The same participant admitted 'I realise now how silly I was, in not correcting my work. I had worked so hard on the article, if only I had the motivation to do so'.

Writing retreats are also acknowledged to allow academics to focus on their writing abilities: a focus group member stated, 'We were required to bring along an article which was half-way done to the retreat for the facilitator to provide us with direction. I learnt how to write an impactful introduction through this intervention and how to make my writing count'. A structured approach, with key focus areas in the actual write-up, does provide the academic with proper direction in developing an article. Sometimes it is the incorrect use or the poor choice of words that reduces the efficacy of the point that needs to be made. Grouped with individuals who share similar knowledge gives the academic the opportunity to enhance their writing skills.

\section{The need for additional support}

The need for additional support was discussed in responses of varying and different kinds. A participant stated, 'I needed the editor's assistance once I wrote the article as well as dedicated time to complete my article’; another stated, 'I require support from other colleagues who will help me finalise this, ones who have published before'. This may imply the need for a rotational or cyclic process of academics sharing workloads to obtain dedicated time off to write. It is posited that the follow through procedure after a writing retreat is what makes the endeavour a successful one. To this end, formulating peer support groups will create the atmosphere for academics to write and publish successfully. 


\section{Lack of time to complete a paper}

This theme was echoed through the responses from participants in other areas already explored in this analysis. One of the participants reiterated, 'I have worked on an article which has its own deadlines and I am afraid I might not meet with that deadline to have it published', another focus group member mentioned, 'it is well and good we have the writing retreats, but not having the time to complete the paper makes this entire effort useless'.

The truth of the matter is that once the academic returns from the writing retreat, $s /$ he is automatically drawn into a predetermined routine. Incorporating writing as part of one's daily tasks might tip the scales in terms of workload, or it can mean that some other task will suffer an attention deficit, as it is absorbed into writing. Moreover, there could be a complete reshuffle of routine to purposefully incorporate the writing task and in all likelihood let the 'administrators administrate' by shifting responsibilities that can be moved to support staff within the department. Ideally there must be an institutional mind shift towards supporting academics to write.

\section{The feeling of isolation}

After a writing retreat, participants felt the need to stay connected to either the facilitator of the writing retreat or members of a group with whom they felt comfortable. This was expressed by two of the interviewed participants as well members of the focus group. Bearing in mind that three of the participants had been academics for less than 10 years and had very weak publication records, the need to stay connected was understandable. This suggests a need for constant communication and validation of certain aspects of the writing task. The participants who were interviewed expressed feelings of isolation, as is evident in the responses '... felt alone', 'needed to communicate with someone more experienced'. Although evidence suggests that there is a need for time away from the normal routine, it seems to be equally important to provide a form of peer support to promote writing abilities, as well as steering academics towards publication. The older more seasoned academics who were part of this study alluded to needing another individual to help them see the process through.

\section{RECOMMENDATIONS}

The key themes that emerged from the experience of the writing retreat which have been identified in this study were:

\section{- $\quad$ Redirected focus on research}


- $\quad$ Beneficial uninterrupted time

- $\quad$ Improved writing abilities.

This implies that writing retreats do provide the academic with many benefits to progress. However, this is not enough to ensure tangible evidence such as a publication that will emerge from such an encounter. Instead it prepares the academic to some degree for that to occur.

This study set out to understand the experience of academics attending a writing retreat, as well as identifying the barriers they encountered after the retreat, which clouded the benefits of the writing retreat experience. Based on these findings, and to ensure continuance after the retreat, this study recommends the following model (see Figure 1). This model considers the attempts made by the institution in capacitating its academics to become prolific authors, and takes this entire process a step further. The findings with respect to barriers academics encountered after the writing retreat was the catalyst for this model.

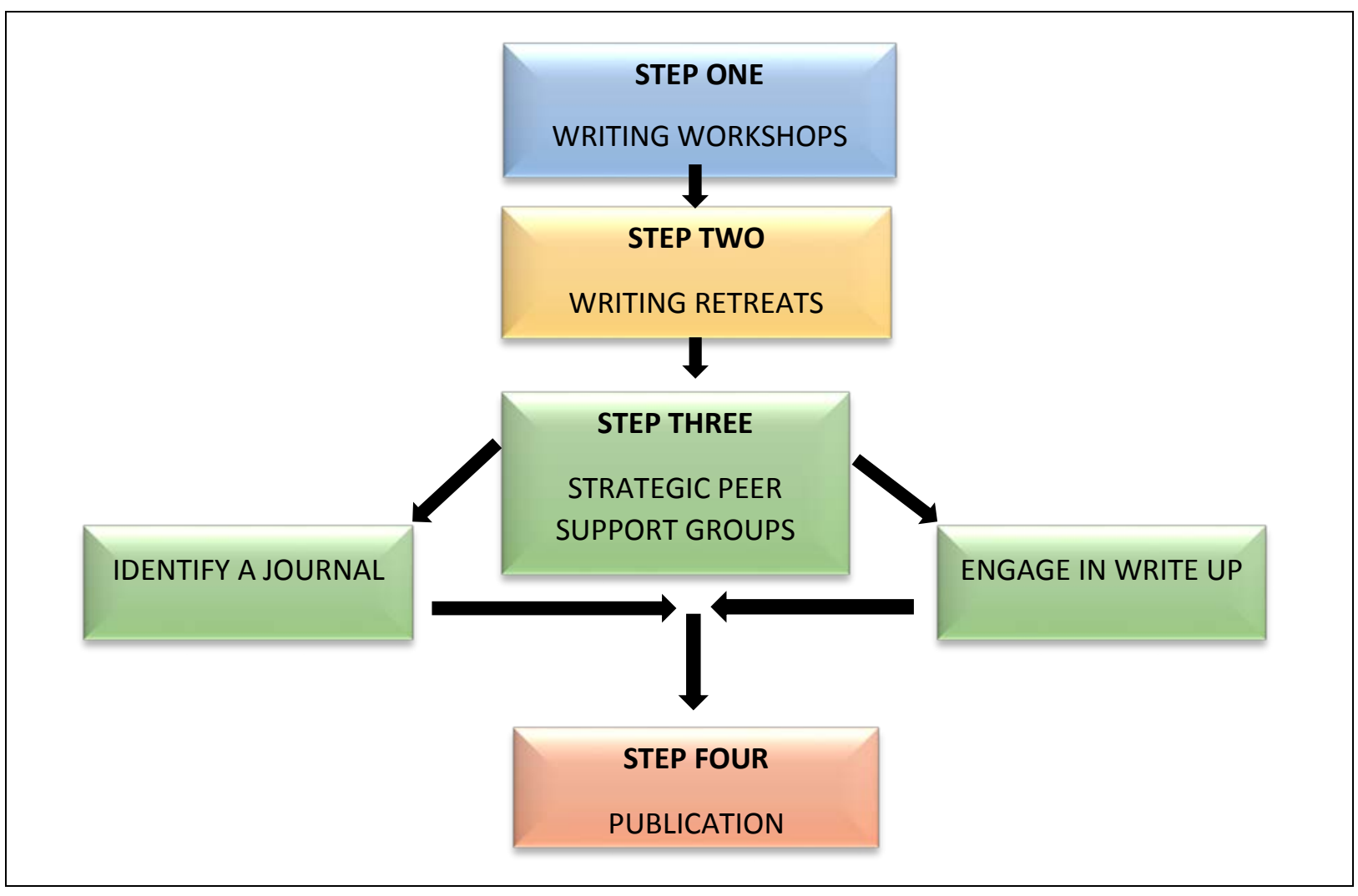

Figure 1. Proposed Model for Publication Improvement

Figure 1, shows four steps which culminate in publication. Each of the steps within this process is outlined to provide clarity, and to explicate its support and relevance to the subsequent steps: 


\section{Step one - Writing workshops}

This step heralds the beginning of a process for academic writers who want to publish. The writing workshop is the institution's initial attempt towards creating an atmosphere for academics to write and to develop their writing skills. Whilst these aims are important, there must also be a needs' assessment conducted for the academic who engages in a writing workshop.

The workshop on 'how to write a paper' is well-established in different academic institutes worldwide. The structure of such a workshop is almost the same in all centres, with minor differences (Eldawlatly 2016). Furthermore, Bojan and Pavlenko (2014) suggest universities which are trying to increase their research presence at an international level, may also use academic writing courses or structures (such as a dedicated writing centre) to achieve this goal. The writing workshop, which usually lasts a few days, is a pre-cursor to the writing retreat.

\section{Step two - Writing retreats}

Writing retreats can be used for the purpose of networking with other like-minded writers, being led by a facilitator to guide the writing process. At this point the 'how-to' process has been achieved. What is established at these retreats, is creating the time and the space for writing to occur. Sometimes, the expectation of the institutions who develop these retreats is that a publication can emerge as a result of attending one of these retreats. Murray (2015) highlights three types of writing retreats: the so-called 'solitary confinement' model, where people write all day in solitude in separate rooms; the 'typing pool' model, where they all write in the same room and the 'hybrid' which is a bit of both. All three have been shown to benefit writers and researchers in a range of disciplines. Rowena Murray (2015) explains that any retreat has its own format, often attuned to the needs of the participants, but that they may share any of the following purposes:

- $\quad$ Prioritising writing over other academic responsibilities

- $\quad$ Making writing personally meaningful in academic and professional work

- $\quad$ Developing the discipline of writing

- $\quad$ Encouraging the level of attention needed for academic writing

- Motivating discussion of research and writing

- Improving writing behaviours and relationships

- Connecting discipline, behaviours and concentration

- Increasing outputs for research assessment/promotion. 
These purposes are all aimed at one objective which is working towards a publication. Kramer and Libhaber $(2016,3)$ report in 2010 and 2011 that two small retreats resulted in eight submissions each. A retreat in 2012 resulted in 186 submissions from 18 groups of which 24 publications emanated from a school where there had been little publication in previous years. Subsequent years saw 92 articles produced and submitted, and in 2014, 12 groups were funded and 38 articles emanated. The positive results generated at the 2012 retreat was as a result of additional funding which catered for the varying needs of academics. As a result, the following types of writing retreats were conducted:

- $\quad$ short (2-3 day) writing retreats which were to be facilitated by mentors (senior staff with publication records), for those who required assistance with writing;

- $\quad$ short (2-3 day) writing retreats which were not facilitated by mentors. These were for academics who were already skilled and did not perceive the need for additional assistance with writing; and

- $\quad$ 'spaced-day' writing retreats, non-facilitated, for those academics who did not wish to be away from their home environment for periods of time, and who preferred not to have concentrated blocks for writing.

Based on the results of Kramer and Libhaber's (2016, 3) study, it can be said that these writing retreat formats may work for some, whilst others might require further components and assistance to obtain positive results. Furthermore, it can be argued that the geo-political context does contribute towards the outcomes of the retreat, and the increased publication output generated.

The feedback from the current study shows that communication between the facilitator and subject (academic) gradually ceased as each was drawn in different directions. Realistically to have one or even two facilitator/s mentor a group of twenty-five academics and still remain in constant contact is a full day's job. With the good intentions of the facilitator acknowledged, it must be said that this is not a sustainable relationship. Quite often the facilitator belongs to a specialized area of interest which may not be shared by others. This too poses a problem. The idea of grouping like-minded individuals together, who share a particular area of expertise or interest, is to provide support to each other during the writing process. Murray and Cunningham (2011, 843) suggest that a retreat does not provide all the development that new researchers need, and that there is a need for further work to develop the relational elements (such as peer 
discussions with other writers), by increasing opportunities for local peer review, building research relationships across institutions, and also by developing ways to balance the demands of teaching and research.

\section{Step three - Strategic peer support groups}

The third step in this process entails engaging with a group during the retreat to ensure continuance once the retreat is over. This will remedy the feeling of isolation expressed by some participants in this study, as the emerging scholar or writer will not feel alone and abandoned. Moreover, in a study conducted by Murray $(2012,774)$ it was found that the leadership role within the retreat setting was positively highlighted by respondents although others also mentioned the need for the leadership role after the retreat. It is noted as important that the mentor/research leader is aware of the responsibility this role demands.

Ideally, to have a mentor or a research leader within a group of two other emerging scholars/writers, can reduce the dynamics experienced within a much larger group. The mentor/research leader within this group must understand the role requirements, such as: being an experienced writer who has already published a few articles; monitoring the group's progress; allocating tasks within the group; locating a journal for publication (which can also be a shared responsibility); locating a conference for presentation; troubleshooting along the way; frequent follow up with group members and ensuring that final drafts meet deadlines.

Engaging in physical meetings might place tremendous pressure on those who have heavy workloads. Technology has created many platforms through which these problems can be mitigated. Currently some institutions engage with students using a Learning Management System (LMS) such as Blackboard. When applied within the context of this model, the uses of Blackboard can be extended to engage with other academics, by creating a class for publication or writing activity, which is used for groups to post their contributions. Similarly, all forms of communication within the group can take place within this environment. This will save the writer from having to move from one place to another, without any loss of time. Murray (2012) suggests that both formal and informal leadership is required, and must contribute towards the functionality of the group. The mentor/research leader within this group will be key to the group's success in publishing. Meetings online via Webex or other platforms can be arranged between members. In an environment that is burdened with multiple tasks carrying equal importance, the online environment provides a way forward despite the challenges experienced by emerging writers.

Grant et al. $(2010,49)$ state that the writers group is perceived by its members to provide 
a supportive environment fostering commitment and enthusiasm to enable the pursuit of writing goals. The supportive element of the group is an important one to ensure the writing task is completed. Grant et al. (2010, 50) report from their study that group members experienced increased confidence in their ability to write, and as time passed, this confidence was transferred to activities outside the group. The benefits of group work cannot be discounted especially when it comes to writing for publication. Through a Social Constructivist approach, learning occurs through frequent group interactions.

At Step three, a journal is sought for the submission of the article. This is not always an easy task, however scanning the proposed journal and its past issues will provide the mentor/research leader or group member with the technical requirements as well as the author guidelines for the journal. Emerging writers must be schooled into taking cognisance of these finer details and how they impact on the development of the article. Furthermore, the responsibility of locating a suitable journal which not only meets with discipline-specific needs but also in terms of its accreditation by various bodies, is imperative, and should be equally borne by all members within the group.

\section{Step four - Publication}

The encouragement, help and practical support from the mentor/research leader as well as other group members will play an important role which may result in the culmination of a completed paper ready for publication. This is the result of every effort that has been directed towards the construction of an article. According to Clark and Thompson (2015), the choices academics make around their work (including, but not only in relation to quality and quantity), are not mere tasks to be performed, but also express, sustain and reinforce personal ideals, as expressed in actions and values (Kamler and Thomson 2014). Thus, different scholars will mindfully approach and express ideals that prioritize a particular kind of scholarly output. In this way, publications function as an important competence indicator in discourses and documents (as represented in the content of the individual's resume) that can be judged by the self, peer and potential employers and function as an expression of scholarly values.

\section{CONCLUDING REMARKS}

The model makes a proposition for a structure which institutions can subscribe to for the enhancement of publications. Steps three and four in the proposed model extend the reach of the writing retreat and provide a way for continued engagement.

This study set out to examine the experience of academics at writing retreats and to 
identify the barriers they experienced once the retreat was over. In response to the findings of the study, a Model for Publication Improvement was proposed which detailed the steps within the process of publishing an article. Two important factors emerged from this model: the valuable role of the mentor/research leader as well as the importance of group work, which suggest a way forward from the writing retreat experience. Through the group's interaction, a sense of collegiality is fostered and the mentor/research leader's contributions are valued. This study supports the findings of Murray and Cunningham (2011) as well as McGrail, Richard and Jones (2006) that universities should support the development of structured interventions for scholars or academics in order to increase their publication output.

\section{REFERENCES}

Bojan, C. and S. Pavlenko. 2014. Needs and attitudes towards academic writing. A practice-informed course structure. Scientific Journal of Humanistic Studies Year 6(11): 80-86.

Clark, A. M. and D. R. Thompson. 2015. But how many papers should I write ...? Making good choices about quality, quantity and visibility of academic publications. Journal of Advanced Nursing 71(8): 1741-1743.

Edmonds, W. A. and T. D. Kennedy. 2013. An applied reference guide to research designs. United Kingdom: Sage.

Eldawlatly, A. A. 2016. Writing paper: Ladder and checklist. Saudi Journal of Anesthesia 10(1): 1-3.

Frantz, J. M. 2012. A faculty development strategy among academics to promote the scholarship of research. African Journal of Health Professions Education 4(2): 118-122.

Grant, M. J., W. Munro, J. McIsaac and S. Hill. 2010. Cross disciplinary writers' group stimulates fresh approaches to scholarly communication: A reflective case study within a higher education institution in the North West of England. New Review of Academic Librarianship 16: 44-64.

Kamler, B. and P. Thomson. 2014. Helping doctoral students write. 2nd Edition. Routledge: New York.

Kramer, B. and E. Libhaber. 2016. Writing for publication: Institutional support provides an enabling environment. BMC Medical Education 16: 115.

MacLeod, I., L. Steckley and R. Murray. 2011. Time is not enough: Promoting strategic engagement with writing for publication. Studies in Higher Education: 1-14.

McGrail, M. R., C. M. Richard and R. Jones. 2006. Publish or perish: A systemic review of interventions to increase academic publication rates. Higher Education Research and Development 25: 19-35.

Miles, M. B. and A. M. Huberman. 1994. Qualitative data analysis. 2nd Edition. Thousand Oaks, CA: Sage Publications.

Murray, R. 2012. Developing a community of research practice. British Educational Research Journal 38(5): 783-800.

Murray, R. 2015. Writing in social spaces: A social process approach to academic writing. London: Routledge.

Murray, R. and S. Moore. 2006. The handbook of academic writing: A fresh approach. Berkshire: McGraw Hill Education.

Murray, R. and E. Cunningham. 2011. Managing researcher development: ‘Drastic transition'? Studies in Higher Education 36(7): 831-845.

Murray, R., L. Steckley and I. Macleod. 2012. Research leadership in writing for publication: A theoretical framework. British Educational Research Journal 38(5): 765-781. 
Steinert, Y., P. McLeod, S. Liben and L. Snell. 2008. Writing for publication in medical education: The benefits of a faculty development workshop and peer writing group. Medical Teacher (30): 280285. 